\title{
Study on the Advantages, Challenges and Countermeasures of Zhuhai in Participating in the Construction of "The Belt and Road" Initiative
}

\author{
Liqin $\mathrm{HU}$ \\ Macau University of Science and Technology \\ Zhuhai City polytechnic
}

\begin{abstract}
The Belt and Road" ("Silk Road Economic Belt" and "21st Century Maritime Silk Road") is a comprehensive opening-up initiative in the new era and also a national vision and action of the country. As the pioneer of reform and opening up, Zhuhai Special Economic Zone should seize this rare historical opportunity in a timely manner, comprehensively analyze Zhuhai's opportunities, advantages and existing risks and challenges in participating in this strategic action, and formulate practical countermeasures and suggestions. In addition, Zhuhai should give full play to the leading role of the government, fully mobilize the enthusiasm of enterprises and nongovernmental organizations, and give full play to the decisive role of the market. The city will also better play the role of spearhead and main force in the improvement of its economic and social development and the smooth implementation of the national "The Belt and Road" strategic action.
\end{abstract}

Keywords-Zhuhai City; "The Belt and Road"; Countermeasures; Suggestions

\section{ANALYSIS ON ZHUHAI'S ADVANTAGES IN} PARTICIPATING IN THE CONSTRUCTION OF "THE BELT AND ROAD" INITIATIVE

As the construction of national "The Belt and Road" proceeded in an orderly way, in May 2015, the Guangdong Provincial Government issued the Implementation Plan for Guangdong Province to Participate in the Construction of "The Belt and Road" (hereinafter referred to as the Implementation Plan), which was the first to achieve the connection with the national "The Belt and Road" strategic planning. Located on the west bank of the Pearl River Estuary, adjacent to Macao and Hong Kong, Zhuhai enjoys a sound basis of cooperation with countries and regions along the Maritime Silk Road as well as a relatively solid economic foundation. Zhuhai not only needs to seize opportunities in time, actively participate in and cooperate with Guangdong's strategy and action, but also become an important member of Guangdong's "spearhead" in "The Belt and Road" construction, because no matter from the perspective of history to reality, o from economy to culture, Zhuhai has many unique advantages that other places do not have.

(1) Unique regional advantages. Zhuhai is located in the center of China's most developed Pearl River Delta Region. It is adjacent to Hong Kong and Macao and faces ASEAN and the South China Sea. It is an important gateway connecting countries along "the 21st Century Maritime Silk Road" and for goods going south to Southeast Asia. It has sea, land and air transportation conditions with strong circulation capacity. In recent years, the cargo throughput of Zhuhai Gaolan Port has exceeded 100 million tons, and it is expected to occupy an important position in the construction of the 21st Century Maritime Silk Road. There is a large regional deep-water port group in the adjacent surrounding area. In terms of aviation, Zhuhai has a special Zhuhai Airport, whose passenger throughput is increasing every year, and an air harbor with Guangzhou Baiyun International Airport as the center. It also has important ports and international aviation hubs connecting the world. The traffic is very convenient. With the rapid construction of Zhuhai Hengqin Free Trade Zone, a new round of reform and innovation has begun in Guangdong Province. The construction of Hong Kong-Zhuhai-Macao Bridge has been accelerated. The Guangzhou-Zhuhai Intercity Railway and the Guangzhou-Zhuhai Railway have been completed and opened to traffic. Major strategic channels such as ShenzhenZhongshan Channel and Shenzhen-Maoming Railway have entered the expectation. Located at the southern end of the Chinese mainland, the important traffic hub role and location advantage of Zhuhai will be more clearly consolidated and highlighted.

(2) Strong economic advantages. As one of the first four special economic zones established in the country and an economically strong city, Zhuhai's economic aggregate has increased year by year, and the economic development has accelerated and improved. According to statistics, at the end of 2015, the GDP of Zhuhai rose from RMB 120 billion at the end of the "11th Five-Year Plan" to RMB 200 billion, the per capita GDP exceeded 20,000 US dollars, and the total social R\&D investment accounted for $2.7 \%$; Fixed assets investment and general public budget revenue doubled from the end of the "11th Five-Year Plan", and the average annual growth rate ranked first in the Pearl River Delta. In the economic structure and development of Zhuhai, Zhuhai actively adjusts the traditional industrial structure, conforms to the new development trend of global industry, and seizes the commanding heights of the industry. The enterprises have strong competitive advantages among "The Belt and Road" countries. With the increase in foreign trade strength, Zhuhai's 
products have a relatively large market expansion space in the countries along the Belt and Road.

(3) Closely connected trade advantages. China Customs magazine released the list of "China's Top 100 Foreign Trade Cities in 2015" in the 7th issue of 2016. Zhuhai ranked 6th in the list with a comprehensive score of 75.3 , second only to Shenzhen, Suzhou, Shanghai, Dongguan and Xiamen. With the implementation of the national "The Belt and Road" strategy, Zhuhai"s economic and trade cooperation with countries along "The Belt and Road" has become more frequent.

(4) Numerous overseas Chinese advantages. Zhuhai is one of the key overseas Chinese hometowns in Guangdong Province. There are numerous compatriots from Hong Kong, Macao and Taiwan and overseas Chinese, covering dozens of countries and regions in the world, mainly distributed in countries along the Maritime Silk Road. And there are many overseas associations of Hong Kong, Macao and Taiwan. Since the reform and opening up, the direct investment of the vast number of overseas Chinese and Hong Kong and Macao compatriots has made significant contributions to the modernization of Zhuhai. The numerous overseas folks are indispensable resources for Zhuhai to participate in the construction of "The Belt and Road". With the implementation of "The Belt and Road" strategy, relying on the advantages of numerous overseas Chinese, Zhuhai's economic development and foreign trade will usher in another golden period of rapid development.

(5) Humanistic advantages of cultural communication. The history of Zhuhai City is not long. However, since the opening of Macao in the 33rd year of Jiajing period of the Ming Dynasty (1554), especially since new China entered the era of reform and opening up in the late 1970s, the land of Zhuhai has had two extremely important influences on the evolution of Chinese civilization, and thus forming the open characteristics of Zhuhai's urban culture. The unique cultural characteristics of Zhuhai are bound to play a unique role of Zhuhai in "The Belt and Road".

\section{PROBLEMS AND CHALLENGES IN ZHUHAI'S PARTICIPATION IN THE CONSTRUCTION OF "THE BELT AND ROAD"}

The advantages of Zhuhai's participation in "The Belt and Road" are unique and obvious, but to turn these advantages into practical results, there are still many problems and challenges. These problems and challenges are mainly reflected in the following aspects.

(1) Faced with more intense internal and external competition. Judging from the current domestic and international situation, the construction of both the "Silk Road Economic Belt" and the "21st Century Maritime Silk Road" faces quite complex external environment and quite fierce competition. First of all, the Western countries dominated by the United States are holding on to China in the relevant regions. The most typical example is the revitalization of manufacturing industry represented by the United States, the acceleration of the return of high-end manufacturing industry, the rise of conservative forces in the developed countries in
Europe, and the serious tendency of trade protectionism. Secondly, Japan, South Korea and the European Union are competing to develop economic and trade relations with ASEAN and India. The competition for regional target markets is increasingly fierce. With the changes in the world structure and regional situation, the rapid development of economic and trade relations between countries will inevitably increase competition. .

(2) Disputes over sovereignty in the South China Sea and issues left over from history As ASEAN is not only a key area of China's foreign trade[1], but also a close neighbor of Zhuhai, it is naturally the first choice for Zhuhai's enterprises and commodities to go out, and the top priority for foreign trade exports of Zhuhai's enterprises. In the foreseeable future, more Zhuhai enterprises going out will choose to cooperate with ASEAN in the future. However, in recent years, around the sovereignty of the South China Sea, countries such as the Philippines and Vietnam have repeatedly stirred up troubles, and the United States and Japan also directly intervenes in the issues of "safety of maritime transportation and navigation" and "freedom of navigation", making the safety of China's maritime trade roads and maritime transportation face more and more difficulties and challenges. If extraterritorial countries provoke troubles and our merchandise trade move further to places such as Africa and Europe, the safety and smoothness of the Straits of Malacca will increase many variables and uncertainties.

(3) Economic situations and the risk of political changes. Because "The Belt and Road" involves many countries, there are different nationalities, different beliefs and huge cultural differences. Due to the lack of sufficient understanding of the countries and regions along "The Belt and Road" route and the great difference in the political, financial and legal environment at home and abroad, friction will be generated in exchanges and cooperation due to different stages of economic development and different requirements. Moreover, because of political instability in some countries, cooperation can be unpredictable. Such large risks and challenges can be resisted by large state-owned enterprises, but for ordinary private enterprises, they are often unaffordable. It has been proved by the twists and turns that have already occurred in projects implemented in Myanmar and Sri Lanka.

(4) Lack of unified layout and overall planning. After "The Belt and Road" strategy was put forward, the relevant departments at the higher level are divided into sections, and the fragmented situation is serious. The situation of "bull management" has not been effectively improved. There is a lack of overall coordination among the relevant local departments, the communication and coordination mechanism between government, private and enterprise is not perfect, and it is difficult to form an effective work force.

(5) There is a clear shortage of talents suitable for the construction of "The Belt and Road". Judging from the actual situation of the manufacturing workers in China, the shortage of middle and senior talents and the irrational talent structure of the too large proportion of primary production and processing personnel are the bottlenecks restricting the optimization and upgrading of China's manufacturing industry. This situation is 
equally prominent in Zhuhai. At present, there are already local vocational colleges in Zhuhai, which can basically meet the needs of local skilled talents. However, in the current situation, it is not enough to rely solely on vocational colleges to train talents for the manufacturing industry. Participating in "The Belt and Road", in addition to highly skilled talents, it also requires talents to have a relatively broad international vision and the basis of multinational culture, so that they can smoothly integrate into the multi-culture of other countries[2]. According to the current talent cultivation specifications of Zhuhai's vocational colleges, there are very few talents with multicultural backgrounds, especially those that can integrate into the culture of Southeast Asian countries, and the actual talent training specifications and quality are also difficult to meet these requirements.

\section{COUNTERMEASURES AND SUGGESTIONS FOR ZHUHAI TO PARTICIPATE IN THE CONSTRUCTION OF "THE BELT AND ROAD"}

Looking into the future, Zhuhai must constantly adapt to the new situation and new requirements, firmly seize the opportunity of China's comprehensive deepening of reform and the profound adjustment of the international economic structure[3], effectively incorporate the participation in the construction of the "21st Century Maritime Silk Road" into the important strategy of Guangdong Province to build an allround opening pattern, and seriously make coordinated development plans. It is necessary to play the leading role of the government, but also give full play to the vitality of the people and the market, achieve the cooperation of government departments, enterprises and other industries on the basis of their respective functions, and strive to better play the role of spearhead and main force in implementing national strategic decisions.

\section{A. Government Departments}

In the implementation of "The Belt and Road" strategy, whether it is to promote economic and trade, expand the scale of import and export trade, or achieve mutual benefit and winwin cooperation and broaden the scope of investment cooperation, it is inseparable from the leading role of the government.

1. Strengthen overall planning. The construction of "The Belt and Road" is both a national strategy and a new national open development initiative and action. To this end, it is necessary for government departments to integrate government agencies, non-government organizations, academics and business forces, coordinate and strengthen strategic planning, speed up the formulation and development of Zhuhai's development plans, further define Zhuhai's development orientation, key tasks and policy measures, and promote the coordination and implementation of major issues. Research and plan a number of major projects, actively communicate with the relevant departments of the state and the province, and strive to include more projects into the national or provincial planning.
2. Deepen regional collaboration. Regional cooperation includes not only coordination and cooperation with neighboring cities, but also cooperation with neighboring countries. In terms of cooperation with neighboring countries, the breakthroughs and key areas are Southeast Asian countries and regions. According to the Quarterly Report on ChinaASEAN Free Trade Area released recently, in the first three quarters of this year, the trade volume of China-ASEAN was 346.597 billion US dollars, accounting for $11 \%$ of China's total foreign trade, with a year-on-year growth of $7.5 \%$. The third quarter was $9 \%$ higher than the second quarter. Zhuhai should focus on this aspect in the future foreign trade. Make full use of the geographical advantages of Zhuhai, which is adjacent to Hong Kong and Macao and located in the economic core zone of the Pearl River Delta, and play the role of Zhuhai as a bridgehead to plan the overall development.

3. Improve policies and regulations. "The Belt and Road" strategy is not only a diplomatic level strategy of the country's foreign relations, but also a systematic project involving economy, politics, culture, law and other fields that requires the active participation of local governments[4]. To this end, Zhuhai should make full use of relevant policies of higher authorities. In the process of the construction of new professional towns and the industrial transformation and upgrading, closely combine the actual conditions of Guangdong and Zhuhai and the relevant supporting policies formulated for the construction of the "21st Century Maritime Silk Road", and timely formulate and improve relevant laws and regulations, to make the role and status of Zhuhai as a trade and transportation hub more prominent and the location advantage in cooperation with countries along the Silk Road more obvious.

4. Conduct propaganda and guidance. The construction of the "21st Century Maritime Silk Road" is the development orientation of promoting Zhuhai's level of economic development and opening-up, creating an upgraded version of Zhuhai's economy and building Zhuhai's "new special zone of ecological civilization and demonstration city of scientific development", and an important task of the proposed "Blue Zhuhai, Science Rising" development strategy. It should continuously increase propaganda, emphasize the openness and inclusiveness of building the "21st Century Maritime Silk Road", highlight the strategic orientation of mutual benefit and common development, and widely invite all sectors of the community and overseas residents to participate in, create a good reputation and atmosphere for the construction of a new starting point of the "21st Century Maritime Silk Road" through the cultural construction and social construction under the guidance of the open development concept, and provide a basic guarantee for the construction and development of the "21st Century Maritime Silk Road". 


\section{B. Enterprises}

1) Comparative Advantages and Constraints

According to the actual situation of Zhuhai and international practices, enterprises should become the pioneer and main body of Zhuhai to participate in the construction of "The Belt and Road". Zhuhai's market economy has a relatively high level of development, and its industrial layout has obvious characteristics. The number of enterprises is large, characterized by labor-intensive processing industry. The industrial products of these enterprises have a relatively large market in developing countries along "The Belt and Road", especially in ASEAN countries. This is also the comparative advantage of Zhuhai's enterprises. Compared with other places in the province, such as Guangzhou and Shenzhen, Zhuhai's enterprises are mostly small and medium-sized. The quantity and scale as a whole are relatively small. Limited by the conditions of the enterprises themselves, most of them process on giving materials and are labor-intensive, with few independent brands and low popularity. Their ability to go out and resist risks is relatively weak, which inhibits the enthusiasm of enterprises to expand overseas markets to a certain extent.

\section{2) Ways and Means of Participation}

According to the characteristics of Zhuhai's enterprises, it can actively participate in the construction of "The Belt and Road" by adopting the ideas and methods of "government-led, enterprise follow-up". The specific strategies are: First, accelerate the cultivation of independent brands and implement brand strategies. Second, build "The Belt and Road" enterprise window on the homepage of the local government website, and continue to expand the reputation of local enterprises with local websites, and cultivate local advantageous industries on this basis; Third, improve financial service functions and preferential tax policies, increase encouragement and support for the development of private enterprises, actively guide and encourage the production and technological innovation of small and medium-sized enterprises and entrepreneurs, and foster leading industries with international competitiveness, and provide more and better high value-added goods and hightech goods for export; Fourth, continue to do a good job of "bringing in" and "going out", strengthen financial investment and cooperation, combine "investment attraction" with "investment selection", and encourage and promote the optimization and upgrading of the export industry structure in the city; Fifth, assist enterprises to do a good job in cultivating and introducing relevant talents.

\section{Other Related Industries}

1) Collaborative Cooperation between Non-governmental Organizations

(1) Strengthen cooperation between non-governmental organizations represented by industry associations. Make good use of the local chambers of commerce and guilds in Zhuhai, deepen the economic and trade cooperation with the Chinese business organizations, overseas Chinese-funded enterprises and counterpart trade associations (chambers of commerce) of countries along the route, make efforts to build local friendship on this basis, and play the role of bridge of Chinese and overseas Chinese. (2) Strengthen the exchange of folk culture and strive to build mutual trust and tolerance, and close social and cultural exchanges. Promote and strengthen the exchanges and cooperation between local universities and countries along "The Belt and Road" in the fields of science and technology, culture, education, medical care, sports, etc., enhance traditional friendship, and form a social foundation featuring mutual trust, integration, inclusiveness and openness.

\section{2) Coordinated Promotion of other Related Industries}

Guide the coordinated promotion of schools and other educational and training institutions, and strengthen the joint cultivation of relevant talents of "The Belt and Road". Competition between countries, competition between places, and competition between enterprises are ultimately the competition for talents. In order to promote the current construction of "The Belt and Road" or from the long-term development of Zhuhai in the future, Zhuhai can learn from the experience and practices of Shenzhen, Dongguan, Foshan and Guangdong Province in building high-level universities, appropriately increase investment in existing universities, and support and encourage qualified colleges and universities to open relevant majors, encourage local colleges and universities to exchange teachers and students with Southeast Asian countries, and encourage education and training institutions to introduce and train high-quality and applicable talents for "The Belt and Road".

\section{CONCLUSIONS}

Zhuhai's participation in the construction of "The Belt and Road" has advantages in location, economy, commerce, overseas Chinese and culture, etc.. It also faces more intense internal and external competition, sovereignty disputes in the South China Sea and historical issues, risk of economic and political changes, the lack of a unified layout and overall planning and the obvious lack of talents and other challenges. These need to play the leading role of the government, but also give full play to the vitality of the people and the market, to achieve the cooperation of government departments, enterprises and other industries on the basis of their respective functions, and strive to better play the role of spearhead and main force in implementing national strategic decisions.

\section{ACKNOWLEDGMENT}

About the author: Liqin HU (1980-), female, from Wuhan, Hubei, a doctoral candidate student of International relations of Institute of Social and Cultural Studies, Macao University of Science and Technology enrolled in 2014, lecturer of Zhuhai City polytechnic. Major research direction: Chinese and foreign cultural exchanges.

Funds: The fourth batch (2014) project of the "12th FiveYear Plan" of Education and Scientific Research in Zhuhai "Study on the Application of Zhuhai's Historical and Cultural Resources in the Teaching of Ideological and Political Theory Course" (2014KTG15). 


\section{REFERENCES}

[1] Jinping XI. Work together to build a China-ASEAN destiny community [N]. People's Daily, 2013-10-04.

[2] Wu CAI. Adhere to Culture First to Build "The Belt and Road" [J]. Qiushi, 2014(9).

[3] Shengxu LIU. On the Beginning of China's "The Belt and Road" Strategy [J]. Financial Economics, 2015(6).

[4] Lei ZOU. Political Economy of China's "The Belt and Road" Strategy [M]. Shanghai People's Publishing House, 2015. 